\title{
Organizational ambidexterity through global strategic partnerships: A cognitive computing perspective
}

\author{
Sarabjot Kaur ${ }^{\mathrm{a}}$, Shivam Gupta ${ }^{\mathrm{b}}$, Sanjay Kumar Singh ${ }^{\mathrm{c}, *}$, Mirko Perano $^{\mathrm{d}}$ \\ ${ }^{a}$ Indian Institute of Technology Kanpur, Department of Industrial and Management Engineering, Kalyanpur, Kanpur 208016, Uttar Pradesh, India \\ ${ }^{\mathrm{b}}$ Montpellier Business School, Montpellier Research in Management, 2300 Avenue des Moulins, 34185 Montpellier, France \\ ${ }^{\mathrm{c}}$ College of Business, Abu Dhabi University, Abu Dhabi, United Arab Emirates \\ ${ }^{\mathrm{d}}$ Reald University College, Department of Management, Vlore, Albania
}

\section{A R T I C L E I N F O}

\section{Keywords:}

Organizational ambidexterity

Cognitive computing

Global strategic partnerships

Qualitative inquiry

Thematic analyses

\begin{abstract}
A B S T R A C T
Cognitive computing holds considerable potential for holistic data interpretation in a dynamic business environment. It can act as an enabler of organizational ambidexterity. The present study explores the potential role cognitive computing can play in an organizational context with global partnerships. The study uses qualitative mode of enquiry and organizational information processing theory as the theoretical framework. Emergent categories were identified using thematic analyses. The key findings of the study highlight the critical gaps in traditional decision systems; cognitive computing as an enabler of ambidextrous orientation and facilitator of informational access for enhanced performance in case of global strategic partnerships.
\end{abstract}

\section{Introduction}

The contemporary world is characterized by fast changing environment. Business organizations are faced with the challenge of keeping pace with developments in the field of technology, markets, cultural and socio-economic structures. All strategic decisions rest on the information processing, analytical and predictive capabilities of the organizations (Dubey et al., 2017). In such a scenario, an ambidextrous and dynamic adjustment approach focused on balance between business continuity and strategic change is the key to firm performance. Ambidextrous organizations are characterized by the agility and adjustment along with strong predictive capabilities and readiness for change (Cegarra-Navarro et al., 2018; Del Giudice et al., 2018a, 2018b; Yu et al., 2018). However, organizational ambidexterity requires continuous monitoring and analysis of market, financial and technological data for decision making in respect of current functioning and future strategy. On one hand, ambidextrous organizations strive to exploit the current business opportunities while maintaining a steady growth, and on the other hand, strive to explore newer business opportunities that align with the overarching vision (Tushman and O'Reilly, 2002). Big corporations face the challenge of having concurrent exploitative and explorative capabilities and processes (Bodwell and Chermack, 2010). Since the organizations are known to be fairly rooted in their present processes and routines (Ketokivi and Schroeder, 2004), a focus towards more dynamic and unconventional business opportunities may not be well served by current capabilities of the incumbent organization.

In such a case, the incumbent organization can utilize its present capabilities for exploitative purposes while join hands with suitable partners for a more innovative and explorative purpose. Thus, global strategic partnerships can augment the current capabilities of the incumbent organization while simultaneously preserving its ambidextrous character. However, in the case of global strategic partnerships, information is required both at regional and global level (Buckley and Ghauri, 2015) and is seen as a crucial resource for a firm's innovation and growth endeavors (Campanella et al., 2017; Caputo, 2017; Shaw and Allen, 2018). Organizations either act on information resulting from structured research or on contingent and unexpected information arising as a result of contemporary happenings and events. While the former has a well-conceived purpose, the latter is often seen as a new resource which can be leveraged for firm's future endeavors (Werhahn et al., 2015).

Opportunities to access relevant information are essential for augmenting and updating the existing knowledge (Choy Chong et al., 2011). A consideration about the significance of information leads the firms to establish ways and means to facilitate knowledge sharing among employees (Al Ahbabi et al., 2018; Caputo and Evangelista,

\footnotetext{
This article belongs to the special section on Micro foundations of Innovation In Global Strategic Partnerships.

* Corresponding author.

E-mail addresses: sarabjot@iitk.ac.in (S. Kaur), sh.gupta@montpellier-bs.com (S. Gupta), sanjay.singh@adu.ac.ae (S.K. Singh), mirko.perano@unireald.edu.al (M. Perano).
} 
2019; Choy Chong et al., 2011; Marin et al., 2016). Information sharing becomes even more significant in a context where multiple actors are engaged (Caputo et al., 2016). Traditional decision support systems including traditional Business Intelligence (BI) along with conventional data analytic techniques which are currently in use in organizations across world (Chen and Lee, 2003; Maas et al., 2016) were developed to harness specific data processing functionalities that can aid data synthesis and analysis useful for key decision areas such as market forecasts, consumer sentiments, financial and economic trends etc. (Chen et al., 2012). These systems work on externally fed market, consumer, financial or production data that is largely structured in nature (Herschel and Jones, 2005). However, contemporary business data is characterized by increasing uncertainty and complexity (Calabrese et al., 2018). With the wide proliferation of web 2.0, there has been a tremendous increase in the availability of unstructured data such as social media sentiments, technological trends, geo-political events, international developments (LaValle et al., 2011; Spangler and Kreulen, 2007). Global Strategic partnerships do not rely only on local knowledge but rather take into account global developments, regulations and geo-political events. In such a scenario, traditional decision support systems of both the incumbent organizations will not suffice to comprehend the complexity of data arising from both structured (like consumer data, market research data, operational data etc.) and unstructured sources (like social media sentiments, geo-political events, global developments, international regulatory changes etc.).

Thus, there is a need of a solution that can combine the decisionmaking functionality with dynamic learning capabilities (Christopoulos et al., 2017). Cognitive computing technology is one such technology inspired by the cognitive capabilities of human mind where computer models capture the learning and analytical capabilities based on the data sets fed to them (Modha et al., 2011). The system also involves a self-learning mechanism thereby inducing dynamic adjustment and improved decision making.

An example of cognitive technology is IBM Watson which finds its application in various domains related to economy and business (Marshall and Lambert, 2018; Sia et al., 2016). IBM Watson has been used to solve business problems such as analyzing huge amounts of customer and market related data for generating business insights (Sia et al., 2016). It also finds its usage in making sense of wide variety of big data to yield insights customized for specific problems such as wealth management and creation of investment portfolio (Sia et al., 2016). While the technology is finding increasing acceptance from various verticals across business, it is being simultaneously enhanced in terms of its functionality and computing abilities. Additionally, business firms are experimenting in terms of deploying this technology in a wide array of business spheres ranging from customer experience to global data management. For instance, organizations are using cognitive technology for direct interaction with customers and enhanced in-store experience by embedding cognitive technology applications with customers' smart-phone devices for in-store usage (Arthur, 2016). On a wider level, it is being used to generate insights based on global data about resources, markets and environmental conditions (Mital et al., 2018; Segars, 2018).

Previous studies have explored the utility of IT based decision support systems in organizational context and thus clearly establish the fact that information processing support helps to reach better solutions and decisions (Benitez et al., 2018; Chen and Lin, 2016; Joshi et al., 2010). However, the existing and widely used decision support tools are inadequate to capture the growing complexity and dynamism inherent in present day business environment (Gupta et al., 2018). Cognitive computing is fast emerging as an alternative to the existing data analytic and processing capabilities of the organization and can serve as an effective business decision support (Gupta et al., 2018; Hernes, 2015; Hurwitz et al., 2015). The role of cognitive technology in supporting decision making has been explored in healthcare (Kohn et al., 2014; Lee, 2014). However, there are limited studies that explore the role of cognitive computing technology in an organizational context (Duan et al., 2019; Gupta et al., 2018; Kliman and Arinze, 2019; Ogiela and Ogiela, 2014). Inter-organizational collaboration or global partnerships have a contextual distinction in terms of scope of operations and domain of decision making, thereby providing a novel ground to explore the potential of cognitive technology in such a scenario. Hence, we explore the potential of cognitive technology in supporting the ambidextrous orientation of the organization having global strategic partnerships.

We use Organizational Information Processing Theory (Galbraith, 1974) as a theoretical basis to explore how cognitive computing technology can act as potential enabler of knowledge integration-based collaborations with global strategic partnerships as a special case.

We further argue that cognitive computing capabilities can serve as a basis for resource and capability leverage for facilitating ambidexterity of incumbent organizations in respect of global strategic partnerships. The article is sequentially structured starting with brief literature review on the concepts of organizational ambidexterity, global strategic partnerships and cognitive computing. The subsequent sections list the research methodology and theoretical framework. Emergent themes derived from thematic analyses of 20 semi-structured interviews highlights major aspects associated with the usage of cognitive systems. We then later discuss the results in light of the extant literature and conclude with implications for theory and practice.

\section{Research background}

\subsection{Organizational ambidexterity}

Studies have noted that when firms operate in a stable environment, they develop well defined and structured systems, hierarchies, roles and responsibilities (Beck and Kieser, 2003). However, on the contrary, the firms that face dynamic business environment develop systems that have relatively less formalization, unstructured jobs and role definitions, and a more flexible system of operational routines (Schreyögg and Sydow, 2010). However, long term success of firms can only be ensured if they adapt their strategic and structural orientation as per the changing environmental and technological scenario (Tushman and O'Reilly, 2002). Thus, organizations face a fundamental challenge of optimally exploiting present market opportunities while simultaneously exploring newer opportunities for future (Koryak et al., 2018; Tushman and O'Reilly, 2002; Wilden et al., 2018). However, exploitation and exploration are essentially divergent orientations involving distinct resources and activities (Guisado-González et al., 2017; Penney et al., 2018). While, the former is associated with continual improvements and efficient implementation, the latter is linked to search for newer alternatives, experimentation and discovery (Wilden et al., 2018). Thus, firms differ in their strategic and structural orientation according to the differences in their environment (Tushman and O'Reilly, 2002). It has been established that organizations need to strike a balance between the alignment and adaptability or exploitation and exploration orientations of the firms (Benner and Tushman, 2003; Eisenhardt and Martin, 2000; Tushman and O'Reilly, 2002). Hence, an ambidextrous orientation is the way forward for both short and long term success.

Organizational ambidexterity is the co-existing orientation towards pursuing incremental and radical innovation at the same time and a provision for accommodating divergent structures and processes characteristic of both (Guisado-González et al., 2017; Simsek, 2009; Tushman and O'Reilly, 2002). It is seen as "an organization's ability to be aligned and efficient in its management of today's business demands while simultaneously being adaptive to changes in the environment" (Raisch and Birkinshaw, 2008). Here, alignment is referred to collective efforts and activities directed towards a common goal, while adaptability is the flexibility to dynamically change and reconfigure tasks, activities and efforts as per the changing environment (Simsek, 2009). Ambidexterity in an organization is viewed at different levels such as 
structural, behavioral and realized levels (Simsek, 2009). Structural ambidexterity operates at a sub unit level involving the creation of distinct sub systems and structural units having unique competencies, processes and organizational culture for meeting the current demands of the market and exploring newer market opportunities (Benner and Tushman, 2003; Simsek, 2009). Different functional sub units like production and marketing \& sales, are assigned either exploitative or explorative functions depending upon market scenario. While the sub units are operating with distinct orientations, they are still bounded together by a universal strategic intent and values of the larger organization (Simsek, 2009).

Behavioral ambidexterity views the organization's capacity to concurrently pursue alignment with the present market demands and adaptability to generate and meet future market demand without necessarily having structurally separate units for the same (Gibson and Birkinshaw, 2004). In such a case, the overall organizational culture is supportive of employees looking out for both present and future business opportunities. While structural and behavioral approaches are explained as the processes to attain an ambidextrous orientation, a realized view on ambidexterity explains a state of attainment of both exploitative and explorative orientations where the firms are simultaneously aligning with the present goals and adapting for future environmental changes (Benner and Tushman, 2003; Simsek, 2009; Smith and Tushman, 2005). Thus, it differs from the structural and behavioral approach in terms of being an end rather than a means. Although organizational ambidexterity is seen by organizational scholars as an approach for long term success, there is a need to understand the ways to achieve such an orientation (Gupta et al., 2006). Since, access to requisite information enables the exploration of potential opportunities for the firm (Pavlou and El Sawy, 2006), it logically follows that in order to attain a state of ambidexterity, knowledge integration and sharing is crucial (Bresciani et al., 2016). Organizations have been known to employ IT enabled capabilities to utilize organizational knowledge for decision making (Benitez et al., 2018). Additionally, such capabilities help to capture external market related information which augments the existing organizational knowledge in form of updates on industry, customers and market competition (Benitez et al., 2018; Joshi et al., 2010; Natalicchio et al., 2018). Availability of aforementioned information is necessary to deal with ongoing market challenges and to explore future opportunities. Organizations are benefitting from their IT capabilities in form of knowledge ambidexterity (Benitez et al., 2018). Thus, an organization's ambidextrous orientation is influenced by the information processing and analytic capabilities and the resultant decision support these systems offers.

\subsection{Global strategic partnerships}

Harnessing the joint capabilities of two or more business organizations is instrumental in growth and expansion of current business operations. The core principle of collaboration i.e. working together with others for a common goal has widely been accepted in all economic and social contexts (Le Pennec and Raufflet, 2018). In context of business, collaboration helps to gain access to knowledge, resources and collective wisdom of two or more organizations (Ozman, 2006; Rathi et al., 2014). This further helps in gaining sustainable growth along with widening the operational horizons of business.

Inter-organizational collaboration helps to lower risk in the exploration of novel business avenues that may later be pursued if found sustainable in the long run (Alexiev et al., 2016). Such a collaboration leads to combination of both informational and knowledge resources from across the two organizations to solve business problems which may not be easy to tackle individually. As the contemporary era demands sustainable solutions to wide array of business problems, collaboration assumes greater importance. Inter-organizational collaboration can help to garner relevant resources and actors that can collectively devise solutions for long-term sustainability (Vaccaro et al.,
2010). Thus, both organizations can mutually benefit and generate value (Le Pennec and Raufflet, 2018). It also helps an organization to manage environmental uncertainties and improve competitive advantage (Gutiérrez et al., 2016).

One such kind of inter-organizational collaboration is global strategic partnerships. It is characterized by the a) common long-term strategy of two or more organizations, b) reciprocal relationship of two organizations, c) global efforts and span of activity of the partners, d) horizontal level relationship as opposed to vertical level relationship, e) preservation of national and ideological identities (Perlmutter and Heenan, 1986). Global strategic partnerships are shifting the strategic focus from firm level to transnational collaborators (Del Giudice et al., 2017; Konsynski and Karimi, 2013). These partnerships are based on collective ownership that ensures alignment in the actions of the two partners who may work independently at an individual firm level (Ostrom, 2000). Technical know-how is the most crucial resource in the present-day technology-driven industry. In this fast-changing world, a stronghold on the technical skills and knowledge drives firm performance. These technology driven industries are process oriented where continuous process improvements are crucial for success and long-term survival. Although large organizations spend a major amount of organizational resources on research and development, there are instances when inherent structural and cultural inflexibility renders delay in adoption of certain innovations (Oliva et al., 2019; Schneckenberg et al., 2015; Schreyögg and Sydow, 2010). In such a case, there is a need to look for solutions and technological innovations outside the organizational boundaries (Brettel and Cleven, 2011).

Global partnerships and alliances enable faster access to technological innovations and know-how with relatively lesser cost (Leischnig et al., 2014). Such arrangements are beneficial as they are more flexible and feasible than irreversible coalitions like mergers. While the two organizations can mutually benefit from collective resources and wisdom, each tends to retain its individuality. Both the organizations are a part of the larger network having mutual complementarities. Recombination of both explicit and tacit knowledge from both the organizations creates a ground for novel ideas and business innovation (Brettel and Cleven, 2011). Oftentimes, certain business and technological tasks involving high levels of tacit knowledge are difficult to replicate and the skills needed to perform them are difficult to document or codify (Bi et al., 2017; Schneckenberg et al., 2015). In such cases, partnerships are the most convenient and suitable way for ensuring fast and timely access to the requisite know-how and tacit knowledge. Global partnerships can make way for access to tacit knowledge that is otherwise difficult to codify. As mentioned before, information processing and analytic capabilities aid organizations in terms of facilitating and influencing decisions. Collaborative and integrated models for decisions support are known to be crucial for success of any international collaboration (Costa et al., 2016). Complementary and integrated collaborative systems yield increased performance in an interorganizational context (Nicolaou, 2011). These collaborative information and decision support systems serve the crucial aspect of knowledge sharing and integration requisite for the enhanced performance of global strategic partnerships.

\subsection{Cognitive computing}

Organizations that operate in a complex, ambiguous and uncertain environment always seek multi-dimensional information. A cognitive approach to managerial decision making considers the role of person's affective and motivational state and accounts for self-referent factors (Dominici et al., 2017; Wood and Bandura, 1989). Similarly, the concept of cognitive computing is inspired by the cognitive capabilities of human mind. It is based on the premise of having a unified computing platform that can mimic human cognitive abilities. Cognitive computing technology aims to coherently combine all functionalities available across segregated and independent computing platforms 
(Modha et al., 2011). It offers mass storage facilities for structured and semi-structured data with large processing capabilities (Williams, 2016). Cognitive computing uses machine learning, artificial intelligence big data, Internet of things and natural language processing functionalities to comprehensively derive solutions to complex problems. It has the capability to process a wide array of data from variety of sources to generate relevant business insights. This technology has functionalities to retain and re-direct previous learning into the system along with integrating it with current contextual peculiarities faced by the firm (Gupta et al., 2018). Learning ability of the system allows for a constant build up of both current and archival data. The system is programmed to develop and analyze hypothesis for problem at hand which is tested against the vast repository of data resources making combined use of the learning, analytical and predictive functionalities.

Cognitive computing can store the metadata such as the details of entities present in the data, the keywords and language used. Such information becomes useful for solving traditional queries and to abstract and synthesize relevant information from a vast repository of structured and semi-structured data (Williams, 2016). While cognitive computing initially found significant application as a decision support in the areas of healthcare (Chen et al., 2016; Kohn et al., 2014; Lee, 2014), it is increasingly finding acceptance as an unprecedented business decision making tool (Gupta et al., 2018; Hernes, 2015; Hurwitz et al., 2015). Cognitive computing functionalities can be utilized to process big data in order to generate business specific insights (Gupta et al., 2018). Thus, it can effectively serve as a decision support for both operational and strategic decision (Hernes, 2015). Cognitive computing can have potential applications in analyzing consumer, financial and investment data along with analyzing socio-economic environmental data directly or indirectly affecting business operations. It facilitates enhanced data processing capabilities that can aid business decisions by means of providing a greater number of alternative solutions and enhanced data processing speed. Cognitive computing also accounts for relevant unstructured data while processing enabling its integration into business decision making, which is otherwise difficult to comprehend by traditional decision support systems (Williams, 2016). Leading corporate organizations have already started reaping the benefit of cognitive computing technologies in business decision making aimed at effective and efficient problem resolution, enhanced productivity and generation of higher revenues (D'Onofrio et al., 2018).

\section{Theoretical framework}

We have utilized Organizational Information processing theory (OIPT) (Galbraith, 1973) as the overarching theoretical framework in the present study. It takes into consideration organizational level needs for information processing with a focus on structural procedures to manage informational flows in uncertain environments (Galbraith, 1974). Additionally, it views information and its management as a crucial factor contributing to organizational performance. OIPT theory proposed that organizations should have requisite information processing capabilities in form of mechanisms, procedures and practices to meet the routine information processing needs of the organization along with dealing with uncertainty arising out of unexpected events in the environment (Galbraith, 1974). Information exchange is vital for fulfilling variety of tasks in an organization (Zhou and Benton Jr, 2007) and information processing capabilities attain greater significance in the case of increased levels of uncertainty (gap between the desired and current levels of information) (Galbraith, 1974). Hence OIPT lays emphasis on establishing firm wide comprehensive mechanisms to ensure availability and processing of relevant information for decision making (Daft and Lengel, 1986). Such mechanisms make a firm capable of analyzing the information in context of its current operations as well as future growth and development (Veldhuizen et al., 2006). Thus, OIPT establishes a need for match between information processing needs and capabilities for any firm. However, apart from intra-organizational context, the concept can be applied to inter-organizational context as well (Kroh et al., 2018).

According to OIPT, an organization can deal with varying degrees of uncertainty by applying different strategies. Conditions of low uncertainty call for lower information processing needs. In such a case, organizations can establish rules and programs, clear vertical hierarchies and target/goal-based coordination (Galbraith, 1974). However, high uncertainty involves greater levels of information processing needs. The management of this scenario requires either a reduction of information processing needs or enhancement in informational processing capabilities. The former can be achieved by creation of "slack resources and self-contained tasks" while the latter can be attained by employing adequate information systems and establishing "lateral relations" (Galbraith, 1973). As discussed in preceding sections, organizational ambidexterity involves an alignment to the present goals and objectives along with a simultaneous adaptation to include more novel strategies and business opportunities (Tushman and O'Reilly, 2002). These two orientations entail different information processing needs with the former characterized by conditions of low and the latter with high level of uncertainty.

Since, favorable organizational performance depends upon the fit between information processing needs and capabilities (Fairbank et al., 2006), we designed the study to include the major perceived challenges in respect of information and knowledge aspects faced by organizations as they strive to achieve operational and strategic performance goals. Information technology acts as a structural mechanism to augment the existing information processing capabilities of the firm by enhancing the nature, scope and amount of information that is processed (BenArieh and Pollatscheck, 2002; Del Giudice et al., 2018a, 2018b) apart from enhancing the ambidextrous orientation of the firm (Soto-Acosta et al., 2018). We, thus, explore the potential impact of cognitive computing technology in augmenting the traditional information processing capabilities. Additionally, uncertainty can be managed by engaging into mutual relationships with external parties in terms of long-term contracts or coalitions (Galbraith, 1974; Fairbank et al., 2006). We, thus, further juxtapose the concept of organizational ambidexterity with global strategic partnership as a potential mode of entering into novel and unexplored areas while still maintaining a stronghold on its core competencies. Access to relevant information and knowledge integration enables better understanding of unexplored market and technological scenarios (Borrás and Edquist, 2013; Sedighi et al., 2016) especially in case of strategic partnerships (Beaugency et al., 2015; Zoo et al., 2017).

Thus, it logically follows that enhanced information processing and analytical capabilities will have a significant impact on the formation and sustenance of such partnerships. Hence, the study has explored the perception of executives about various issues, opportunities and challenges that cognitive computing technology can offer for ambidextrous organization opting for global strategic partnerships.

\section{Research methods}

The study is primarily aimed to know how cognitive computing technology can aid in achieving ambidextrous orientation in organizations in the context of global strategic partnerships. We adopted a qualitative mode of enquiry using a semi-structured interview technique. The questions were structured around the issues in current decision support systems and perceived usability of cognitive computing technology in the context of global strategic partnerships. The qualitative nature of this research aims to uncover potential issues and aspects associated with usage of cognitive computing technology in an inter-organization collaboration context. Detailed responses help in understanding the phenomenon inductively and to observe the interplay of different concepts. Such research is exploratory and not explanatory (establishing relational causations) (Crouch and McKenzie, 2006). The relatively flexible approach is well suited for generating 
insights into phenomenon for which there is little prior research. Hence, smaller samples that range from 15 to 20 allow for a close association between researcher and respondent thereby enabling in-depth insights into a phenomenon (Crouch and McKenzie, 2006; Robinson, 2014). Thus, as per the given guidelines, we interviewed 20 executives who are working in major business organizations in UAE. These executives occupy key positions in the organization with decision making powers in the firm. Furthermore, the number of executives selected was in accordance with the sample size guidelines for qualitative studies (Crouch and McKenzie, 2006; Lincoln and Guba, 1985; Mason, 2010; Robinson, 2014). Our sample size of 20 executives also falls within the minimum acceptable sample range for qualitative studies ( 15 being the minimum acceptable sample) (Guest et al., 2006 as cited in Mason, 2010). The executives who participated are holding key positions and are eligible to provide firm and industry specific insights about the potential role of cognitive computing technology in facilitating ambidextrous orientation of the organization having global strategic partnerships.

Thematic analyses were used to identify emergent themes from the data (Braun and Clarke, 2006). The process involves inductive theory generation from qualitative data (Fereday and Muir-Cochrane, 2006). Data patterns are identified and coded for analysis and for bringing out major themes. These themes are then logically linked together for the formation of major categories (Braun and Clarke, 2006). UAE is one of the world's top 20 countries in respect of ease of doing business (Doing Business Report, 2018). The country hosts a large number of multinationals and has collaboration with international bodies for business partnerships ("UAE-US Partnerships," n.d.). UAE is fast developing its industrial base focusing on economic diversification aimed at positioning the country as a major global trade hub ("Best countries for Business," 2018). Since UAE provides very conducive conditions for fostering international collaborations on technology and business front, we considered it as a relevant and suitable context to explore potential interplay of ambidextrous orientation and global partnerships.

The demographic details of the respondents are listed in three different tables. Their age and education qualification is listed in Table 1. The work experience of the respondents is shown in Table 2 which is followed by the details of their role in the organization in Table 3. The semi structured interview schedule with indicative questions (Binder and Edwards, 2010; Malhotra and Grover, 1998) is also included as Appendix A. We have maintained the anonymity of the respondents and hence their identity has been masked. They are referred to as R1 to R20.

The research findings are supported by relevant literature from various academic journals articles, industry white papers and other archival resources. This is done with an aim of triangulating the research findings through the use of multitude of data sources to ensure their reliability and validity (Voss, 2010). Triangulation is a crucial technique that helps in eliminating researcher's bias by taking into account data from a variety of sources to ensure rigor and richness of research findings (Eisenhardt, 1989; Flick, 2007; Yin, 2004). Usage of data from different sources makes the study more comprehensive and increases reliability of research results (Jonsen and Jehn, 2009). Fig. 1 summarizes the details of research methodology.

Table 1

Age group of the respondents and their educational qualifications.

\begin{tabular}{lcccc}
\hline \multirow{2}{*}{ Age group } & \multicolumn{2}{l}{ Educational qualification } & Total \\
\cline { 2 - 4 } & Graduate & Post-graduate & $\mathrm{PhD}$ & \\
\hline $20-30$ & 2 & 2 & - & 4 \\
$31-40$ & 1 & 9 & 2 & 12 \\
$41-50$ & 1 & 3 & - & 4 \\
Total & 4 & 14 & 2 & 20 \\
\hline
\end{tabular}

Table 2

Number of employees in the company/institution and their work-experience.

\begin{tabular}{lccccc}
$\begin{array}{l}\text { Number of employees } \\
\text { in company/ } \\
\text { institution }\end{array}$ & \multicolumn{3}{l}{ Total work experience } & & \multicolumn{2}{c}{ Total } \\
\cline { 2 - 5 } & 1-3 years & $3-5$ years & $5-10$ years & $\begin{array}{l}\text { More than } \\
10 \text { years }\end{array}$ & \\
\hline $10-50$ & - & - & - & 1 & 1 \\
$50-300$ & - & - & 1 & 2 & 3 \\
$300-500$ & - & - & - & 1 & 1 \\
$500-1000$ & 1 & - & 1 & - & 2 \\
More than 1000 & - & 2 & 3 & 8 & 13 \\
Total & 1 & 2 & 5 & 12 & 20 \\
\hline
\end{tabular}

\section{Findings}

Qualitative data was analyzed to generate sub themes and major themes which are explained in the sub-sections below. Tables 4 and 5 illustrate the process of thematic analysis.

\subsection{Critical gaps in the traditional decision support systems}

In order to understand the operational level challenges with the traditional decision support systems, we asked our respondents about the various issues they face while working with these traditional systems. Respondents noted that existing decision support systems were having many critical gaps that surface during real time decision making. The key challenges that our respondents noted are listed below.

\subsubsection{Informational delay}

Respondents noted that one of the biggest difficulties while working with traditional systems is that of delay in getting the requisite information. Since the system works on delivering accurate information at the right time, any error on this account will directly affect the decision-making process. Although this informational delay is beyond the technical purview of the data processing functionalities, it still affects the larger decision support system. Respondent R5 noted, "One of the biggest challenges is not receiving accurate information. Sometimes the information is delivered so late that it really costs us in terms of badly affecting the schedule especially in case of fast track projects. Also, it decreases the productivity of my team." Hence, informational delays not only negatively affect the efficiency and effectiveness of decision making but also costs organizations in terms of reducing employee productivity.

\subsubsection{Lack of comprehensive analysis}

Traditional systems operate according to set of pre-defined rules (Chen and Lee, 2003). These systems are programmed to account for defined roles and domain specific information for data analysis. However, our respondents noted that traditional systems at times are inconsistent with the structural and operational routines of the incumbent organization. As one of the respondents R10, noted that, "The linkage of business rules and specific domain knowledge with the system is lacking in most of the systems." Traditional systems account for structured data that is highly organized and seamlessly accessible. However, our respondents noted that there are instances when they are faced with unanticipated circumstances that require access to information that is not a part of available database. Such scenarios are not adequately considered in traditional decision support systems. As one of the respondents R15 noted that, "Sometimes there is a lack of old data...often times, there are unforeseen circumstances and disruptions which are not considered in the present system we are using." A similar observation was made by another respondent (R8), "As for the Data-Driven DSS, sometimes when there is a new project or task that has several options that we must choose from, is not available in the database, mostly because it is the first time the company is required to work on such a project or task. This 
Table 3

Domain of the work of the respondents and their role in the company/institution.

\begin{tabular}{|c|c|c|c|c|c|}
\hline \multirow[t]{2}{*}{ Domain of your work } & \multicolumn{4}{|c|}{ Role in company/institution } & \multirow[t]{2}{*}{ Total } \\
\hline & Consultant & Director/CXO/Founder & Engineer & Manager/Sr. Manager & \\
\hline Banking/insurance/financial services & - & - & - & 1 & 1 \\
\hline Construction/real estate/infrastructure & - & - & 1 & 1 & 2 \\
\hline Consulting & - & - & 1 & - & 1 \\
\hline Government & 1 & 1 & 1 & 6 & 9 \\
\hline Human resource (HR) & - & - & - & 1 & 1 \\
\hline Manufacturing & - & - & 3 & 2 & 5 \\
\hline Transport/aviation & - & - & - & 1 & 1 \\
\hline Total & 1 & 1 & 6 & 12 & 20 \\
\hline
\end{tabular}

means that more research has to be done through other methods to get enough data to be able to make a decision."

\subsection{Cognitive computing based knowledge integration and sharing in context of global strategic partnerships}

Informational delays and lack of comprehensive analytical abilities can substantially affect decision making in an organization. This affect can be even more significant in case of global partnerships which may present unanticipated scenarios and highly unstructured information environment. Our respondents noted that emerging technological developments like cognitive computing can be useful in such cases in the following ways:

\subsubsection{Comprehensive insights}

Our respondents noted that cognitive computing technology can be instrumental in achieving comprehensive insights based on variety of unstructured and structured data. Unlike the traditional system which has predefined logics, cognitive systems based on advanced analytical and learning capabilities can help uncover newer areas for exploration of business opportunities. As one of the respondents R14 noted that, "Having a strategic partnership with a company which has cognitive computing based technology can be really helpful...such an alliance will bring together resources and shared wisdom. All this combined with novel insights uncovered by cognitive technology can be immensely useful to explore new and different business opportunities." Another respondent R17 noted that, "Cognitive computing can explore various patterns that we (human analysts) cannot identify by analyzing the data. This technology can ensure that our strategic decisions like exploration of newer markets are well informed."

\subsubsection{Continual learning}

Our respondents noted that organizations can leverage learning and analytical abilities of cognitive computing technology to assist decision making in unstructured and dynamic environments in which global strategic partnerships operate. Continual learning is an important antecedent for innovation and sustainable long-term performance (Giuliani and Bell, 2005). Cognitive computing technology involves the functionalities of machine learning and artificial intelligence combined with language processing. Thus, the system 'continually learns' and bases future interpretations taking into account previous results (Gupta et al., 2018; Williams, 2016). Our respondents considered this continual learning ability useful for ensuring a comprehensive analysis of the information available from both the organizations. The insights derived in one scenario can be utilized to generate even richer insights for subsequent scenarios. Respondent R5 made an observation in this regard and told that, "If one area of company has been improved due to use of cognitive computing, then other areas could benefit from the same activity and use the insights available to future improvements." Similar was the observation of another respondent R12, "Global partnerships lead to sharing of all the main issues, lessons learned and success stories among the partner. Cognitive computing can help to derive interpretations based on this shared knowledge."

\subsubsection{Task based knowledge integration}

Cognitive computing technology can be useful for combining specific information from a variety of sources (Williams, 2016). The organizations can utilize this functionality of cognitive computing to integrate specialized knowledge available with the organizations and to derive relevant task specific interpretations. This is evident by the observations made by one of the respondents R7, "A smart cognitive computing system will be able to merge the knowledge data bases and experiences

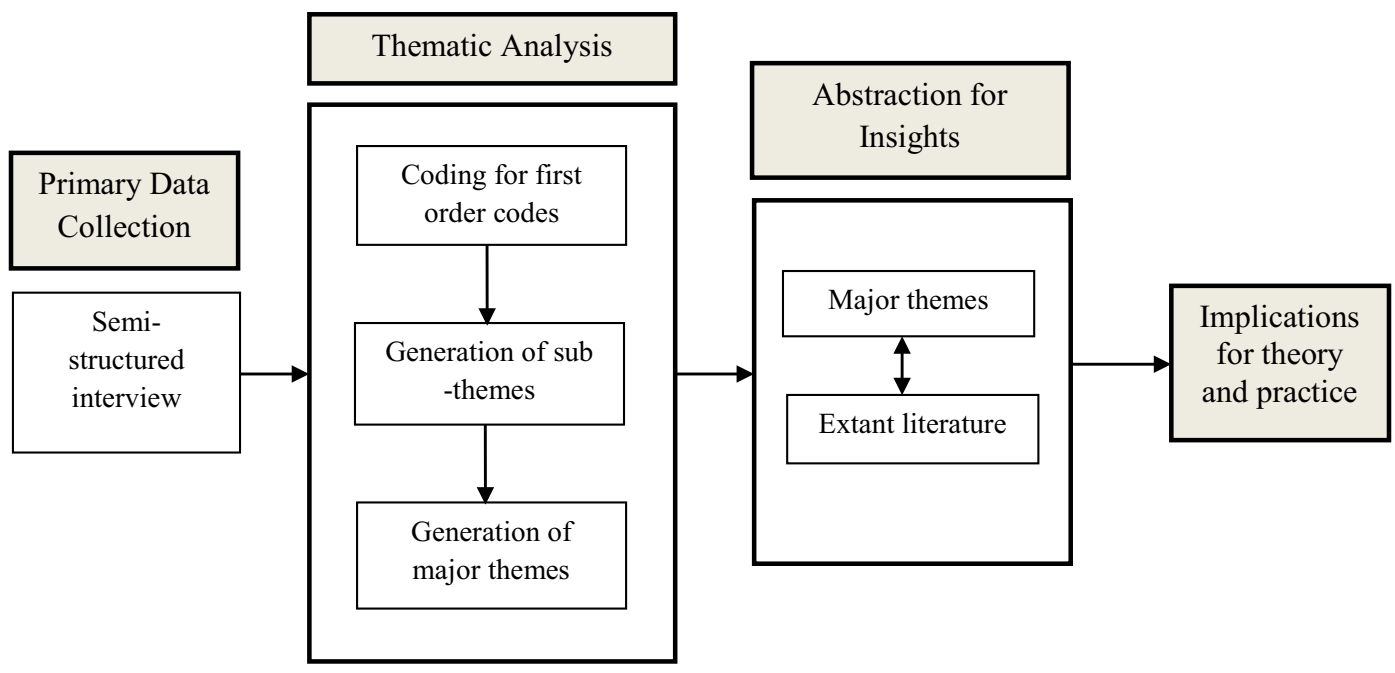

Fig. 1. Illustration of steps followed in qualitative data collection and thematic analysis. 
Table 4

Generation of initial codes from primary data.

\begin{tabular}{|c|c|c|}
\hline S.no. & Extract from primary data & Initial codes \\
\hline 1. & $\begin{array}{l}\text { "One of the biggest challenges is not receiving accurate information. Sometimes the information is delivered so late } \\
\text { that it really costs us in terms of badly affecting the schedule especially in case of fast track projects. Also, it } \\
\text { decreases the productivity of my team." (R5) }\end{array}$ & $\begin{array}{l}\text { Lack of requisite information } \\
\text { Informational delays } \\
\text { Effects productivity }\end{array}$ \\
\hline 2. & $\begin{array}{l}\text { "It can collect accurate and large data from several processes and inputs in operation in short time along with real } \\
\text { time data which can help decision makers." (R19) }\end{array}$ & $\begin{array}{l}\text { (Cognitive computing) capability to handle large } \\
\text { data sets } \\
\text { (Cognitive computing) capability to handle real time } \\
\text { data } \\
\text { Support for decision making }\end{array}$ \\
\hline 3. & $\begin{array}{l}\text { "In my opinion one of the shortcomings of a cognitive computing technology will be the ability to understand } \\
\text { relationships between the organization and the other organizations. An example of that might be a trust } \\
\text { relationship between our construction company and a client. Sometimes we decide to go with a decision that on } \\
\text { paper seems to be bad, but it is done to keep a good relationship with the client, as sometimes they are also willing } \\
\text { to lose some profit to keep the relationship between both organizations." (R9) }\end{array}$ & $\begin{array}{l}\text { System's lack of understanding of trust and client } \\
\text { relationship issues } \\
\text { Decision made on the basis of trust and prior } \\
\text { relationship } \\
\text { Client relationships as important consideration }\end{array}$ \\
\hline 4. & $\begin{array}{l}\text { "A smart cognitive computing system will be able to merge the knowledge data bases and experiences from all } \\
\text { parties; and with that the system will be able to provide decisions more clearly and more beneficial, in addition to } \\
\text { being able to cover a wider range of knowledge area that the companies alone didn't have sufficient data about." } \\
\text { (R7) }\end{array}$ & $\begin{array}{l}\text { Wide range of information as input } \\
\text { Perceived usability in terms of decision support } \\
\text { Shared information in case of partnerships. }\end{array}$ \\
\hline 5. & $\begin{array}{l}\text { "As for the Data-Driven DSS, sometimes when there is a new project or task that has several options that we must } \\
\text { choose from, is not available in the database, mostly because it is the first time the company is required to work on } \\
\text { such a project or task. This means that more research has to be done through other methods to get enough data to } \\
\text { be able to make a decision." (R8) }\end{array}$ & $\begin{array}{l}\text { Inadequacy of information in existing decision } \\
\text { support system } \\
\text { Historical data rendered useless for novel scenarios } \\
\text { Research based information support. }\end{array}$ \\
\hline
\end{tabular}

Table 5

Generation of final themes by combining sub-themes.

\begin{tabular}{|c|c|}
\hline Sub-themes & Final themes \\
\hline Informational delay & \multirow{5}{*}{$\begin{array}{l}\text { Critical gaps in the traditional decision } \\
\text { support systems } \\
\text { Cognitive computing based knowledge } \\
\text { integration and sharing in context of global } \\
\text { strategic partnerships }\end{array}$} \\
\hline Lack of comprehensive analysis & \\
\hline Comprehensive insights & \\
\hline Continual learning & \\
\hline $\begin{array}{c}\text { Task based knowledge } \\
\text { integration }\end{array}$ & \\
\hline $\begin{array}{c}\text { Potential support for operational } \\
\text { decisions }\end{array}$ & \multirow[t]{2}{*}{$\begin{array}{c}\text { Cognitive computing capabilities as basis for } \\
\text { ambidextrous orientation }\end{array}$} \\
\hline $\begin{array}{c}\text { Potential support for strategic } \\
\text { decisions }\end{array}$ & \\
\hline Resistance to change & \multirow[t]{3}{*}{ Cognitive computing adoption challenges } \\
\hline Non-inclusion of tacit knowledge & \\
\hline High investment & \\
\hline
\end{tabular}

from all parties; and with that the system will be able to provide decisions more clearly and more beneficial, in addition to being able to cover a wider range of knowledge area that the companies alone didn't have sufficient data about." Similarly, respondent R9 noted that, "Unfortunately many global partnerships are dealing with the challenge of knowledge integration as there are budget related problems. Cognitive computing can be utilized to bridge the gap of knowledge integration, but the acceptance is low at the moment."

\subsection{Cognitive computing capabilities as basis for ambidextrous orientation}

Ambidextrous organizations have a dual orientation of exploitation of current business opportunities and exploration for newer business and market avenues. Since business involves decision making at every step, adequate information can yield suitable alternatives to make an informed choice. Our respondents have observed that cognitive computing can help to integrate information and knowledge required for both operational (exploit) decisions and strategic (explore) decisions.

\subsubsection{Potential support for operational decisions}

Our respondents perceived that inclusion of cognitive computing in place of traditional decision support systems can help deriving insights which can lead to formulation of more efficient and effective solutions to routine operational issues. Respondent R1 noted that, "In my opinion it will be mostly helpful in making low risk decisions that are made daily like checking for the best supplier to go with, based on the available budget, required quality, and project duration." Another respondent R11 noted that, "Sometimes even if there are other suppliers and sub-contractors who might be able to bring higher profit to company, the company goes with the same suppliers and sub-contractors, just because they don't want to risk dealing with new companies. But a cognitive computing aid system might be able to show that it is better for the company if the suppliers and sub-contractors were changed." Respondent R19 noted that cognitive computing can help in keeping projects on track by analyzing real time data. He made an observation that, "It can collect accurate and large data from several processes and inputs in operation in short time along with real time data which can help decision makers. In project, it can help controlling of the schedule and cost especially with accurate data of the construction activities and monitoring the spending."

\subsubsection{Potential support for strategic decisions}

Cognitive computing functionalities can be utilized to uncover future possibilities by analysis of huge amount of market and technological data available outside the organizational boundaries along with data about internal processes and capabilities. Our respondents made similar observations. Respondent R17 stated that, "It accelerates, enhances human expertise. It can derive deeper insights with employees, bridge gaps between insights and innovations. It can understand people better. It can improve communication and solve business challenges." Another respondent R18 noted that, "There is a lot of data that is generated in my organization and we are not capable of handling and analyzing this data. Cognitive computing can analyze all kinds of data so that my company can possibly explore new potential business opportunities." Similarly, respondent R10 noted that, "Cognitive computing can help in integrating different data types in the planning process while allowing the system to identify and analyze the association within the data at faster pace. It eliminates human bias. It uncovers multiple innovative opportunities across organizations." Organizations can leverage the insights generated by cognitive computing to explore opportunities that may then be pursued by means of strategic alliance in form of global strategic partnerships.

\subsection{Cognitive computing: adoption challenges}

While cognitive computing has many potential benefits, there are some pertinent issues in respect of its adoption. A few of these issues highlighted by our respondents include concerns about data security, resistance to change and considerably high costs of implementation. 


\subsubsection{Resistance to change}

Every technological change entails resistance on the part of employees. Respondents expressed concerns over the possibility of replacement of human analysts and subsequent unemployment along with lack of sufficient technological skills as a major reason for potential resistance. As R11 noted that, "Old employees may not find it comfortable to work with a new technology. The change in technological developments is so fast...it has become difficult even for corporations to keep up with the pace." Another respondent R17 made a similar observation, "Acceptance by the user of CC systems is going to be a major challenge. Technology is being developed at a fast pace, but the skills of the employees are not upgraded with this pace. Thus, acceptance and ease of use of such systems will be an issue from the soft side of the work. At the same time, physical infrastructure to handle smooth functioning of CC based systems is a challenge now. The technological expertise both in terms of software and hardware in this field varies from country to country and company to company."

\subsubsection{Non-inclusion of tacit knowledge}

Decision support systems provide analytical support for yielding several possible alternatives for choice. While the systems can support information aggregation and analysis, the final decision rests with the executives who also exercise judgment and intuition while making the final decision (Fahimnia, 2018). Thus, there is an important role of tacit considerations, which are not fully accounted by decision support systems. Cognitive systems can include a lot of unstructured input for interpretation; however, our respondents perceived that it might not still be adequate to represent softer issues like trust. Respondent R9 highlighted that, "In my opinion one of the shortcomings of a cognitive computing technology will be the ability to understand relationships between the organization and the other organizations. An example of that might be a trust relationship between our construction company and a client. Sometimes we decide to go with a decision that on paper seems to be bad, but it is done to keep a good relationship with the client, as sometimes they are also willing to lose some profit to keep the relationship between both organizations."

\subsubsection{High investment}

Majority of respondents expressed concerns over the high investment costs involved in adopting this technology. As the technology is still evolving, most of the respondents told that this technology may add up to costs in terms of infrastructural costs, human resources deployment, regular skill enhancements and organization wide reconfigurations. In the words of respondent R12, "There is no doubt that cognitive technology has the potential to offer a lot of advantages for organizations. But, in my opinion there will huge investment costs associated with adoption of this technology." Another respondent (R13) noted that adoption of this technology will increase employee training and retention costs, "Availability of manpower to handle such systems is a challenge and then to retain the same manpower. In addition, it is going to be crucial to ensure that the work force should be exposed to regular training so that they are not outdated. All these involve more costs to the company."

\section{Discussion}

The preceding sections highlighted some major aspects in context of present study. The perceived gaps in respect of usage of traditional decision support systems point to growing need for shift to more advanced and sophisticated technological solutions. Technology does not operate in isolation and needs a holistic system to be operational with a collective aim to achieve organizational goals (Demetis and Lee, 2017). Studies have shown that traditional decision support systems are growing obsolete in wake of changing nature of data and advancement in analytical technique (Hou, 2012; Brooks et al., 2015). Growing complexity of business environment has rendered these systems as inadequate in processing a host of dynamic variables having a direct or indirect effect on the organizational operations (Edge et al., 2018;
Richards et al., 2017). We have found similar results in respect of issues in usage of traditional systems. Lack of adequate information for processing will render the system ineffective. Additionally, lack of comprehensive analysis by traditional systems is another crucial aspect that points to the need for improved and inclusive analytical system.

Although big data and predictive analytics have opened a plethora of data processing capabilities, cognitive systems surpass their functionalities in terms of nature, extent and range of data they process and interpret (Gupta et al., 2018). Thus, an explicit need for an improved system paves the way for exploring the perceived usability of cognitive systems. Additionally, as it is known that organizations face the challenge of informational inadequacy and lack of functional ability to foresee future opportunities (Heger and Rohrbeck, 2012; Zhu and Porter, 2002), any technology that bridges this knowledge gap can become an enabler for fostering ambidextrous orientation. As discussed, cognitive systems can provide decision alternatives relevant for routine operational decisions as well as insights for exploration of a novel field. While the present systems can augment strategic planning by forecasting trends, cognitive system hold the potential for uncovering newer areas that may be completely unexpected and unexplored (Gupta et al., 2018). Thus, the system holds promise in terms of much needed knowledge synthesis that can closely relate to human decision making. Such functionality can provide an organization with sufficient level of informational and analytical advantage in order to augment its routine and strategic operations. Hence, we find that cognitive computing is a potential enabler for organizational ambidexterity.

While cognitive computing based analysis can lead to possible avenues for exploration, the organization may not be able to devote its own resources to its execution because of structural and functional inflexibilities (Heracleous et al., 2017). However, one of the most pursued routes for expanding the organizational stream of operations is strategic alliance or partnerships. Global strategic partnerships help to access the innovation and technological development of partner organization without changing much of its present structure (Ostrom, 2000). Although the two organizations retain their individuality, they are bound together by a collective vision. Cognitive computing technology can benefit both the organizations by its capabilities to integrate the shared information and knowledge resources. As previously discussed in Findings section, the comprehensive analysis of information can yield insights that can further augment the joint resources and collective expertise in context of global strategic partnerships. The two organizations not only differ in terms of their operational focus but also in terms of culture and regional distinctions (Gomes et al., 2016). Crafting a joint strategy for future operations would require a consideration of these differences. Cognitive systems are perceived to be useful in such a scenario as they can take into account multitude of unstructured and structured information for deriving insights that can improve the chances of successful long-term decisions (Williams, 2016).

Additionally, the continual learning abilities have been perceived to reduce the chances of repetitive mistakes and to take the decisional orientation of organization into account while giving future interpretations. This offers an opportunity for both the partner organizations to arrive at consensual decisions more often, thus saving on time and resources (Vendrell-Herrero et al., 2018). Task oriented knowledge integration is perceived to lessen the cognitive load of executives thereby allowing them to focus attention on tacit aspects like relationship management, building trust or skill improvements. Thus, cognitive computing has a lot to offer in terms of increased access to relevant insights offered through sophisticated information processing and analytical techniques. The results of the study have been collectively represented in a conceptual model shown in Fig. 2. The figure highlights the informational flows and presents a logical sequence of the various concepts in action. Beginning from structured and unstructured data the sequential flow leads to business insights and further to analytical support for ambidextrous orientation. A backward loop highlights the continual learning ability of the organization. 


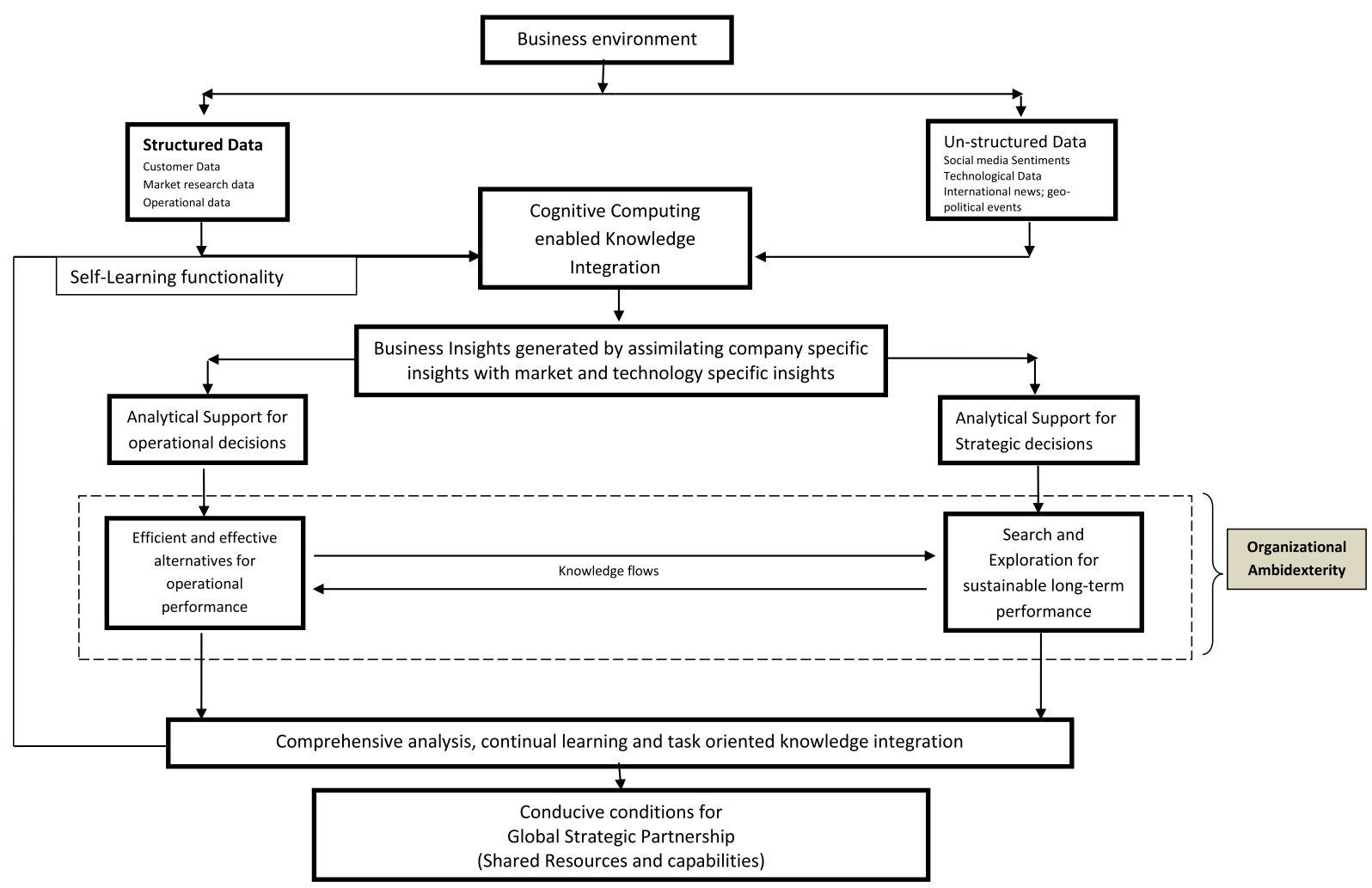

Fig. 2. Holistic conceptualization of cognitive computing enabled organizational ambidextrous orientation in context of global strategic partnerships.

Although cognitive computing has its own advantages, there are some major concerns in its adoption at a wider scale. Technological changes come at a cost (Amankwah-Amoah, 2017). However, adoption decisions take into account long-term benefits as well. As highlighted in the findings, high costs of investments are a major issue. However, costs can be lowered by engaging into alliances and partnerships with organizations. Additionally, the aspect of non-inclusion of tacit knowledge can be managed by holistically taking into account managerial intuition and experience while selecting the alternatives.

\section{Implications}

\subsection{Implications for theory}

Cognitive computing has a lot of potential for managing the growing informational complexity of the present business environment. The study highlighted the major issues and concerns in respect of perceived usability of cognitive computing technology in context of organizations having global operations. It presents an opportunity for academicians working in the domain of organizational and technology related research to consider the mutual impact of the organization wide strategic orientation and technology potentialities, in general, with an understanding of potential impact of cognitive computing as a facilitator of long-term sustainable growth, in particular. Since, cognitive computing technologies are in the initial phase of adoption, the present study contributes in terms of bringing forth perceived challenges and issues in the process of transition from traditional systems to cognitive computing technology. Moreover, the unique context of organizational ambidexterity and global strategic partnerships makes an interesting backdrop for exploring the potential of such technologies. The study contributes to the organization and innovation literature in terms of stating the potential benefits of embedding cognitive computing technology as a part of larger decision-making system in the firm. Hence, it advances an understanding of how a technological change can drive a change in operational orientation of the firm. Thus, it holds implications for scholars engaged in the study of firm level technology induced changes. From the perspective of technology studies, it gives an indication of how the introduction of cognitive technology can extend the existing information processing capabilities of a firm. Additionally, it furthers an understanding of organizational ambidexterity from the lens of organizational information processing theory.

\subsection{Implications for practice}

Cognitive technology can support the informational requirements for strategic alliances such as global strategic partnerships and can make way for exploration of novel business avenues. The study has implications for managers as it provides a broader framework for understanding the interplay and relationship of cognitive technology in the context of global strategic partnerships along with providing an understanding about the potential role it can play in creating enabling conditions for fostering ambidexterity in organizations. Managers can derive practical insights about the potential benefits of adopting such a technology. Since, this technology is relatively new and evolving, such insights can prove useful for organization level strategies for its adoption. An understanding about the potential of cognitive technology to affect the operational and strategic decisions provides a ground for the managers and executives to consider the shift towards cognitive technology. Aspects such as task-based knowledge integration and continual learning abilities are very relevant to the contemporary business context and point to the utility of adopting cognitive computing technology for business operations. This can have direct implications on the firm performance in the long run. A synergistic combination of two firms in case of global partnership is of strategic importance to both the firms. The study presents managers and executives with an understanding of how cognitive technology can create grounds for a meaningful engagement in such an arrangement. The study has highlighted how cognitive systems account for continual learning which well aligns with the need for organizational learning. Hence, it holds implications in respect of understanding how cognitive technology can help in 
simplification and better management of organizational knowledge.

\section{Limitations and future scope of research}

We acknowledge the conceptual and exploratory nature of the present study. The study represents a more contextualized scenario which further needs empirical support for generalizable results. Global strategic partnerships presented a rich context for emergence of key aspects associated with potential of cognitive technology in case of inter-organizational collaborations. Although the context had its own specifics, it limited the scope of research to similar organizational level alliances at a broader level. Future research can explore the potential of cognitive technology in varied contexts spanning other functional pillars of management such as production (product life cycles, production scheduling), marketing (new product development, consumer sentiments, market disruptions), operations (Supply chain and logistics) and finance (capital investment decisions, financial market sentiments). Such research can look into various organizational and individual level aspects of adoption namely, structural reconfigurations or changed managerial role definitions. Additionally, empirical studies at a larger scale can be conducted for ensuring its applicability to a wider scale and scope. Such studies can aim to establish relationships among different variables involved in its potentialities, adoption, implementation and usage in varied contexts.

\section{Appendix A. Semi-structured interview schedule used for generating insights from respondents}

1. What kind of decision support system you use for day-to-day functioning?

2. What are the various challenges that you face with the current decision support system?

3. In your opinion, what are the key decision areas that can be positively affected by the adoption of cognitive computing technology?

4. How can cognitive computing aid in the day-to-day business operations and decision making of your organization?

5. How can cognitive computing augment the exploration of potential business opportunities for your organization?

6. How can global strategic partnerships (like joint ventures and strategic alliances) help in exploration of new business opportunities?

7. How can cognitive computing be utilized for knowledge integration in case of global strategic partnerships?

8. In your opinion, what are the major issues in respect of adopting the emerging cognitive computing technology in place of traditional analytics-based decision support systems?

\section{References}

Al Ahbabi, S.A., Singh, S.K., Balasubramanian, S., Gaur, S.S., 2018. Employee perception of impact of knowledge management processes on public sector performance. J. Knowl. Manag. https://doi.org/10.1108/JKM-08-2017-0348. (Online).

Alexiev, A.S., Volberda, H.W., Van den Bosch, F.A., 2016. Interorganizational collaboration and firm innovativeness: unpacking the role of the organizational environment. J. Bus. Res. 69 (2), 974-984.

Amankwah-Amoah, J., 2017. Integrated vs. add-on: a multidimensional conceptualisation of technology obsolescence. Technol. Forecast. Soc. Chang. 116, 299-307.

Arthur, R., 2016. Macy's Teams With IBM Watson for AI-Powered Mobile Shopping Assistant. Forbes July 20. Retrieved from. https://www.forbes.com/sites/ rachelarthur/2016/07/20/macys-teams-with-ibm-watson-for-aipowered-mobileshopping-assistant/\#4aad3b8b7f41.

Beaugency, A., Sakinç, M.E., Talbot, D., 2015. Outsourcing of strategic resources and capabilities: opposing choices in the commercial aircraft manufacturing. J. Knowl. Manag. 19 (5), 912-931.

Beck, N., Kieser, A., 2003. The complexity of rule systems, experience and organizational learning. Organ. Stud. 24 (5), 793-814.

Benitez, J., Castillo, A., Llorens, J., Braojos, J., 2018. IT-enabled knowledge ambidexterity and innovation performance in small US firms: the moderator role of social media capability. Inf. Manag. 55 (1), 131-143.

Benner, M.J., Tushman, M.L., 2003. Exploitation, exploration, and process management: the productivity dilemma revisited. Acad. Manag. Rev. 28, 238-256.

Ben-Arieh, D., Pollatscheck, M.A., 2002. Analysis of information flow in hierarchical organizations. Int. J. Prod. Res. 40 (15), 3561-3573.

Best Countries for Business, 2018. Retrieved from. https://www.forbes.com/places/ united-arab-emirates/.

Bi, J., Sarpong, D., Botchie, D., Rao-Nicholson, R., 2017. From imitation to innovation: the discursive processes of knowledge creation in the Chinese space industry. Technol. Forecast. Soc. Chang. 120, 261-270.

Binder, M., Edwards, J.S., 2010. Using grounded theory method for theory building in operations management research: a study on inter-firm relationship governance. Int. J. Oper. Prod. Manag. 30 (3), 232-259.

Bodwell, W., Chermack, T.J., 2010. Organizational ambidexterity: integrating deliberate and emergent strategy with scenario planning. Technol. Forecast. Soc. Chang. 77 (2), 193-202.

Borrás, S., Edquist, C., 2013. The choice of innovation policy instruments. Technol. Forecast. Soc. Chang. 80 (8), 1513-1522.

Braun, V., Clarke, V., 2006. Using thematic analysis in psychology. Qual. Res. Psychol. 3 (2), 77-101.

Bresciani, S., Ferraris, A., Del Giudice, M., 2016. R\&D internationalization in Asian developing countries: evidence from European multinationals. Mark. Compet. 25-44. https://doi.org/10.3280/MC2016-003003.

Brettel, M., Cleven, N.J., 2011. Innovation culture, collaboration with external partners and NPD performance. Creat. Innov. Manag. 20 (4), 253-272.

Brooks, P., El-Gayar, O., Sarnikar, S., 2015. A framework for developing a domain specific business intelligence maturity model: application to healthcare. Int. J. Inf. Manag. 35 (3), 337-345.

Buckley, P.J., Ghauri, P. (Eds.), 2015. International Business Strategy: Theory and Practice. Routledge.

Calabrese, M., Iandolo, F., Caputo, F., Sarno, D., 2018. From mechanical to cognitive view: the changes of decision making in business environment. In: Social Dynamics in a Systems Perspective. Springer, Cham, pp. 223-240.

Campanella, F., Della Peruta, M.R., Del Giudice, M., 2017. The effects of technological innovation on the banking sector. J. Knowl. Econ. 8 (1), 356-368.

Caputo, F., 2017. Reflecting upon knowledge management studies: insights from systems thinking. Int. J. Knowl. Manag. Stud. 8 (3/4), 177.

Caputo, F., Evangelista, F., 2019. Information sharing and cognitive involvement for sustainable workplaces. In: Corporate Social Responsibility: Concepts, Methodologies, Tools, and Applications. IGI Global, pp. 1403-1420.

Caputo, F., Giudice, M.D., Evangelista, F., Russo, G., 2016. Corporate disclosure and intellectual capital: the light side of information asymmetry. Int. J. Manag. Financ. Account. 8 (1), 75-96.

Cegarra-Navarro, J.G., Jiménez-Jiménez, D., García-Pérez, A., Del Giudice, M., 2018. Building affective commitment in a financial institution through an ambidexterity context. Eur. Bus. Rev. 30 (1), 2-25.

Chen, J.Q., Lee, S.M., 2003. An exploratory cognitive DSS for strategic decision-making. Decis. Support. Syst. 36 (2), 147-160.

Chen, S., Lin, N., 2016. Global dispersion of offshore service providers: an information processing perspective. J. Knowl. Manag. 20 (5), 1065-1082.

Chen, H., Chiang, R.H., Storey, V.C., 2012. Business intelligence and analytics: from big data to big impact. MIS Q. 1165-1188.

Chen, Y., Argentinis, J.E., Weber, G., 2016. IBM Watson: how cognitive computing can be applied to big data challenges in life sciences research. Clin. Ther. 38 (4), 688-701.

Choy Chong, S., Salleh, K., Noh Syed Ahmad, S., Syed Omar Sharifuddin, S.I., 2011. KM implementation in a public sector accounting organization: an empirical investigation. J. Knowl. Manag. 15 (3), 497-512.

Christopoulos, G.I., Liu, X.X., Hong, Y.Y., 2017. Toward an understanding of dynamic moral decision-making: model-free and model-based learning. J. Bus. Ethics 144 (4), 699-715.

Costa, E., Soares, A.L., de Sousa, J.P., 2016. Information, knowledge and collaboration management in the internationalisation of SMEs: a systematic literature review. Int. J. Inf. Manag. 36 (4), 557-569.

Crouch, M., McKenzie, H., 2006. The logic of small samples in interview-based qualitative research. Soc. Sci. Inf. 45 (4), 483-499.

Daft, R.L., Lengel, R.H., 1986. Organizational information requirements, media richness and structural design. Manag. Sci. 32 (5), 554-571.

Del Giudice, M., Arslan, A., Scuotto, V., Caputo, F., 2017. Influences of cognitive dimensions on the collaborative entry mode choice of small-and medium-sized enterprises. Int. Mark. Rev. 34 (5), 652-673.

Del Giudice, M., Scuotto, V., Garcia-Perez, A., Petruzzelli, A.M., 2018a. Shifting wealth II in Chinese economy. The effect of the horizontal technology spillover for SMEs for international growth. Technol. Forecast. Soc. Chang. https://doi.org/10.1016/j. techfore.2018.03.013. (Online).

Del Giudice, M., Soto-Acosta, P., Carayannis, E., Scuotto, V., 2018b. Emerging perspectives on business process management (BPM): IT-based processes and ambidextrous organizations, theory and practice. Bus. Process. Manag. J. 24 (5), 1070-1076.

Demetis, D.S., Lee, A.S., 2017. Taking the first step with systems theorizing in information systems: a response. Inf. Organ. 27 (3), 163-170.

Doing Business Report: Economies of Middle East \& North Africa Carry Out Record Reforms to Improve Business Climate. Retrieved from. https://www.worldbank.org/ en/news/press-release/2018/10/31/doing-business-report-economies-of-middleeast-north-africa-carry-out-record-reforms-to-improve-business-climate.

Dominici, G., Yolles, M., Caputo, F., 2017. Decoding the dynamics of value cocreation in consumer tribes: an agency theory approach. Cybern. Syst. 48 (2), 84-101.

D'Onofrio, S., Franzelli, S., Portmann, E., 2018. Advancing cognitive cities with the web of things. In: New Advances in the Internet of Things. Springer, Cham, pp. 75-91.

Duan, Y., Edwards, J.S., Dwivedi, Y.K., 2019. Artificial intelligence for decision making in the era of Big Data-evolution, challenges and research agenda. Int. J. Inf. Manag. 48, 63-71. 
Dubey, R., Gunasekaran, A., Childe, S.J., Papadopoulos, T., Luo, Z., Wamba, S.F., Roubaud, D., 2017. Can big data and predictive analytics improve social and environmental sustainability? Technol. Forecast. Soc. Chang. https://doi.org/10.1016/ j.techfore.2017.06.020. (Online).

Edge, D., Larson, J., White, C., 2018. Bringing AI to BI: enabling visual analytics of unstructured data in a modern business intelligence platform. In: Extended Abstracts of the 2018 CHI Conference on Human Factors in Computing Systems. ACM, pp. CS02 April.

Eisenhardt, K.M., 1989. Building theories from case study research. Acad. Manag. Rev. 14 (4), 532-550.

Eisenhardt, K.M., Martin, J.A., 2000. Dynamic capabilities: what are they? Strateg. Manag. J. 21 (10-11), 1105-1121.

Fahimnia, B., 2018. Integrating Human Judgement into Quantitative Forecasting Methods: A Review. Omega (In Press).

Fereday, J., Muir-Cochrane, E., 2006. Demonstrating rigor using thematic analysis: a hybrid approach of inductive and deductive coding and theme development. Int J Qual Methods 5 (1), 80-92.

Flick, U., 2007. Concepts of Triangulation. Managing Quality in Qualitative Research. pp. 38-54.

Galbraith, J.R., 1973. Designing Complex Organizations. Addison-Wesley, Reading, Mass. Galbraith, J.R., 1974. Organization design: an information processing view. Interfaces 4 (3), 28-36.

Gibson, C.B., Birkinshaw, J., 2004. The antecedents, consequences, and mediating role of organizational ambidexterity. Acad. Manag. J. 47, 209-226.

Giuliani, E., Bell, M., 2005. The micro-determinants of meso-level learning and innovation: evidence from a Chilean wine cluster. Res. Policy 34 (1), 47-68.

Gomes, E., Barnes, B.R., Mahmood, T., 2016. A 22 year review of strategic alliance research in the leading management journals. Int. Bus. Rev. 25 (1), 15-27.

Guest, G., Bunce, A., Johnson, L., 2006. How many interviews are enough? An experiment with data saturation and variability. Field Methods 18 (1), 59-82.

Guisado-González, M., González-Blanco, J., Coca-Pérez, J.L., 2017. Analyzing the relationship between exploration, exploitation and organizational innovation. J. Knowl. Manag. 21 (5), 1142-1162.

Gupta, A.K., Smith, K.G., Shalley, C.E., 2006. The interplay between exploration and exploitation. Acad. Manag. J. 49, 693-706.

Gupta, S., Kar, A.K., Baabdullah, A., Al-Khowaiter, W.A., 2018. Big data with cognitive computing: a review for the future. Int. J. Inf. Manag. 42, 78-89.

Gutiérrez, R., Márquez, P., Reficco, E., 2016. Configuration and development of alliance portfolios: a comparison of same-sector and cross-sector partnerships. J. Bus. Ethics 135 (1), 55-69.

Heger, T., Rohrbeck, R., 2012. Strategic foresight for collaborative exploration of new business fields. Technol. Forecast. Soc. Chang. 79 (5), 819-831.

Heracleous, L., Papachroni, A., Andriopoulos, C., Gotsi, M., 2017. Structural ambidexterity and competency traps: insights from Xerox PARC. Technol. Forecast. Soc. Chang. 117, 327-338.

Hernes, M., 2015. Performance evaluation of the customer relationship management agent's in a cognitive integrated management support system. In: Transactions on Computational Collective Intelligence XVIII. Springer, Berlin, Heidelberg, pp. 86-104.

Herschel, R.T., Jones, N.E., 2005. Knowledge management and business intelligence: the importance of integration. J. Knowl. Manag. 9 (4), 45-55.

Hou, C.K., 2012. Examining the effect of user satisfaction on system usage and individual performance with business intelligence systems: an empirical study of Taiwan's electronics industry. Int. J. Inf. Manag. 32 (6), 560-573.

Hurwitz, J.S., Kaufman, M., Bowles, A., 2015. Cognitive Computing and Big Data Analytics. John Wiley \& Sons.

Jonsen, K., Jehn, K.A., 2009. Using triangulation to validate themes in qualitative studies. Qual. Res. Org. Manag. Int. J. 4 (2), 123-150.

Joshi, K.D., Chi, L., Datta, A., Han, S., 2010. Changing the competitive landscape: continuous innovation through IT-enabled knowledge capabilities. Inf. Syst. Res. 21 (3), 472-495.

Ketokivi, M., Schroeder, R., 2004. Manufacturing practices, strategic fit and performance: a routine-based view. Int. J. Oper. Prod. Manag. 24 (2), 171-191.

Kliman, R., Arinze, B., 2019. Cognitive computing: impacts on financial advice in wealth management. In: Aligning Business Strategies and Analytics. Springer, Cham, pp. $11-23$.

Kohn, M.S., Sun, J., Knoop, S., Shabo, A., Carmeli, B., Sow, D., Syed-Mahmood, T., Rapp, W., 2014. IBM's health analytics and clinical decision support. Yearb. Med. Inform. 23 (01), 154-162.

Konsynski, B.R., Karimi, J., 2013. The information technology and management infrastructure strategy globalization and information management strategies. In: Strategic Information Management. Routledge, pp. 103-126.

Koryak, O., Lockett, A., Hayton, J., Nicolaou, N., Mole, K., 2018. Disentangling the antecedents of ambidexterity: exploration and exploitation. Res. Policy 47 (2), 413-427.

Kroh, J., Luetjen, H., Globocnik, D., Schultz, C., 2018. Use and efficacy of information technology in innovation processes: the specific role of servitization. J. Prod. Innov. Manag. 35 (5), 720-741.

LaValle, S., Lesser, E., Shockley, R., Hopkins, M.S., Kruschwitz, N., 2011. Big data, analytics and the path from insights to value. MIT Sloan Manag. Rev. 52 (2), 21.

Le Pennec, M., Raufflet, E., 2018. Value creation in inter-organizational collaboration: an empirical study. J. Bus. Ethics 148 (4), 817-834.

Lee, H., 2014. Paging Dr. Watson: IBM's Watson supercomputer now being used in healthcare. J. AHIMA 85 (5), 44-47.

Leischnig, A., Geigenmueller, A., Lohmann, S., 2014. On the role of alliance management capability, organizational compatibility, and interaction quality in interorganizational technology transfer. J. Bus. Res. 67 (6), 1049-1057.

Lincoln, Y.S., Guba, E.G., 1985. Naturalistic Inquiry. Sage, Newbury Park, CA.

Maas, J.B., van Fenema, P.C., Soeters, J., 2016. ERP as an organizational innovation: key users and cross-boundary knowledge management. J. Knowl. Manag. 20 (3), 557-577.

Malhotra, M.K., Grover, V., 1998. An assessment of survey research in POM: from constructs to theory. J. Oper. Manag. 16 (4), 407-425.

Marin, A., Cordier, J., Hameed, T., 2016. Reconciling ambiguity with interaction: implementing formal knowledge strategies in a knowledge-intensive organization. J. Knowl. Manag. 20 (5), 959-979.

Marshall, T.E., Lambert, S.L., 2018. Cloud-based intelligent accounting applications: accounting task automation using IBM watson cognitive computing. J. Emerging Technol. Account. 15 (1), 199-215.

Mason, M., 2010. Sample size and saturation in $\mathrm{PhD}$ studies using qualitative interviews. In: Forum Qualitative Sozialforschung/Forum: Qualitative Social Research. vol. 11(3) August.

Mital, M., Del Giudice, M., Papa, A., 2018. Comparing supply chain risks for multiple product categories with cognitive mapping and analytic hierarchy process. Technol. Forecast. Soc. Chang. 131, 159-170.

Modha, D.S., Ananthanarayanan, R., Esser, S.K., Ndirango, A., Sherbondy, A.J., Singh, R., 2011. Cognitive computing. Commun. ACM 54 (8), 62-71.

Natalicchio, A., Ardito, L., Messeni Petruzzelli, A., Del Giudice, M., 2018. The origins of external knowledge inflows and the impact of university technologies. RD Manag. https://doi.org/10.1111/radm.12354. (Online).

Nicolaou, A.I., 2011. Integrated information systems and interorganizational perfor mance: the role of management accounting systems design. In: Advances in Accounting Behavioral Research. Emerald Group Publishing Limited, pp. 117-141.

Ogiela, L., Ogiela, M.R., 2014. Cognitive systems for intelligent business information management in cognitive economy. Int. J. Inf. Manag. 34 (6), 751-760.

Oliva, F.L., Semensato, B.I., Prioste, D.B., Winandy, E.J.L., Bution, J.L., Couto, M.H.G., Singh, S.K., 2019. Innovation in the main Brazilian business sectors: characteristics, types and comparison of innovation. J. Knowl. Manag. 23 (1), 135-175.

Ostrom, E., 2000. Collective action and the evolution of social norms. J. Econ. Perspect. 14 (3), 137-158.

Ozman, M., 2006. Knowledge integration and network formation. Technol. Forecast. Soc. Chang. 73 (9), 1121-1143.

Pavlou, P.A., El Sawy, O.A., 2006. From IT leveraging competence to competitive advantage in turbulent environments: the case of new product development. Inf. Syst. Res. 17 (3), 198-227.

Penney, C.R., Combs, J.G., Gaffney, N., Sexton, J.C., 2018. A jack-of-all-trades or a master of none: the performance effects of balancing exploration and exploitation within vs across alliance portfolio domains. J. Knowl. Manag. https://doi.org/10.1108/JKM09-2017-0395. (Online).

Perlmutter, H.V., Heenan, D.A., 1986. Cooperate to compete globally. Harv. Bus. Rev. 64 (2), 136-152.

Raisch, S., Birkinshaw, J., 2008. Organizational ambidexterity: antecedents, outcomes, and moderators. J. Manag. 34 (3), 375-409.

Rathi, D., M. Given, L., Forcier, E., 2014. Interorganisational partnerships and knowledge sharing: the perspective of non-profit organisations (NPOs). J. Knowl. Manag. 18 (5), 867-885.

Richards, G., Yeoh, W., Chong, A.Y.L., Popovič, A., 2017. Business intelligence effectiveness and corporate performance management: an empirical analysis. J. Comput. Inf. Syst. 1-9.

Robinson, O.C., 2014. Sampling in interview-based qualitative research: a theoretical and practical guide. Qual. Res. Psychol. 11 (1), 25-41.

Schneckenberg, D., Truong, Y., Mazloomi, H., 2015. Micro foundations of innovative capabilities: the leverage of collaborative technologies on organizational learning and knowledge management in a multinational corporation. Technol. Forecast. Soc. Chang. 100, 356-368.

Schreyögg, G., Sydow, J., 2010. Crossroads—organizing for fluidity? Dilemmas of new organizational forms. Organ. Sci. 21 (6), 1251-1262.

Sedighi, M., van Splunter, S., Brazier, F., van Beers, C., Lukosch, S., 2016. Exploration of multi-layered knowledge sharing participation: the roles of perceived benefits and costs. J. Knowl. Manag. 20 (6), 1247-1267.

Segars, A.H., 2018. Seven technologies remaking the world. In: MIT Sloan Management Review, Executive Guide, Retrieved online at. https://sloanreview.mit.edu/ projects/seven-technologies-remaking-the-world/.

Shaw, D.R., Allen, T., 2018. Studying innovation ecosystems using ecology theory. Technol. Forecast. Soc. Chang. 136, 88-102.

Sia, S.K., Soh, C., Weill, P., 2016. How DBS Bank pursued a digital business strategy. MIS Q. Exec. (2), 15

Simsek, Z., 2009. Organizational ambidexterity: towards a multilevel understanding. J. Manag. Stud. 46 (4), 597-624.

Smith, W., Tushman, M., 2005. Managing strategic contradictions: a top management model for managing innovation streams. Organ. Sci. 16, 522-536.

Soto-Acosta, P., Popa, S., Martinez-Conesa, I., 2018. Information technology, knowledge management and environmental dynamism as drivers of innovation ambidexterity: a study in SMEs. J. Knowl. Manag. 22 (4), 824-849.

Spangler, S., Kreulen, J., 2007. Mining the Talk: Unlocking the Business Value in Unstructured Information. IBM Press.

Tushman, M.L., O'Reilly, C.A., 2002. Winning through Innovations. Harvard Business School Press, Boston.

UAE-US Partnerships Retrieved from. https://www.uae-embassy.org/uae-us-relations/ key-areas-bilateral-cooperation/uae-us-partnerships\#business.

Vaccaro, A., Parente, R., Veloso, F.M., 2010. Knowledge management tools, inter-organizational relationships, innovation and firm performance. Technol. Forecast. Soc. 
Chang. 77 (7), 1076-1089.

Veldhuizen, E., Hultink, E.J., Griffin, A., 2006. Modeling market information processing in new product development: an empirical analysis. J. Eng. Technol. Manag. 23 (4), 353-373.

Vendrell-Herrero, F., Gomes, E., Bustinza, O.F., Mellahi, K., 2018. Uncovering the role of cross-border strategic alliances and expertise decision centralization in enhancing product-service innovation in MMNEs. Int. Bus. Rev. 27 (4), 814-825.

Voss, C., 2010. Case research in operations management. In: Researching Operations Management. Routledge, pp. 176-209.

Werhahn, D., Mauer, R., Flatten, T.C., Brettel, M., 2015. Validating effectual orientation as strategic direction in the corporate context. Eur. Manag. J. 33 (5), 305-313.

Wilden, R., Hohberger, J., Devinney, T.M., Lavie, D., 2018. Revisiting James March (1991): whither exploration and exploitation? Strateg. Organ. 16 (3), 352-369.

Williams, S., 2016. Outthink cognitive hype: creating a business-driven cognitive strategy. Bus. Intell. J. 21, 28-36.

Wood, R., Bandura, A., 1989. Social cognitive theory of organizational management. Acad. Manag. Rev. 14 (3), 361-384.

Yin, R.K., 2004. The Case Study Anthology. Sage, Thousand Oaks, CA.

Yu, X., Tao, Y., Tao, X., Xia, F., Li, Y., 2018. Managing uncertainty in emerging economies: the interaction effects between causation and effectuation on firm performance. Technol. Forecast. Soc. Chang. 135, 121-131.

Zhou, H., Benton Jr., W.C., 2007. Supply chain practice and information sharing. J. Oper. Manag. 25 (6), 1348-1365.

Zhu, D., Porter, A.L., 2002. Automated extraction and visualization of information for technological intelligence and forecasting. Technol. Forecast. Soc. Chang. 69 (5) 495-506.
Zoo, H., de Vries, H.J., Lee, H., 2017. Interplay of innovation and standardization: exploring the relevance in developing countries. Technol. Forecast. Soc. Chang. 118, 334-348.

Sarabjot Kaur, is at Indian Institute of Technology Kanpur, Department of Industrial and Management Engineering, Uttar Pradesh, India. Her research interests includes organizational ambidexterity, qualitative research and grounded theory. She can be reached at sarabjotime@gmail.com.

Shivam Gupta, Ph.D. is at Montpellier Business School, Montpellier, France. His research interest includes big data analytics, cloud computing, cognitive computing, and supply chain management. He can be reached at sh.gupta@montpellier-bs.com.

Sanjay Kumar Singh, Ph.D., is Associate Professor of Management, College of Business, Abu Dhabi University, Abu Dhabi, UAE. His research interests include, big data analytics, knowledge management, innovation management, sustainability, international HRM and SMEs. He can be reached at sanjay.singh@adu.ac.ae.

Mirko Perano hold a double Ph.D., one at University of Rome "La Sapienza" (IT) and one at University of Huelva (ES). He is Vice-Rector (acting Rector) and Director of Department of Management at Reald University College, Albania. In the last 10 years he wrote as author some books on strategic management, project management and corporate social responsibility and journal papers on strategic management, value (co)creation, open innovation and tourism. He can be reached at mirko.perano@unireald.edu.al. 